\title{
A DIDÁTICA A PARTIR DE PEDAGOGOS CONTEMPORÂNEOS
}

\author{
DIDÁCTICA DESDE PEDAGOGOS CONTEMPORÁNEOS
}

DIDACTICS FROM CONTEMPORANEOUS PEDAGOGUES

\author{
Rosana de Oliveira Rodrigues DANTAS ${ }^{1}$ \\ Cloves Santos de MORAES ${ }^{2}$ \\ Edivania Gomes da SILVA ${ }^{3}$ \\ Osmar Hélio Alves ARAÚJO ${ }^{4}$
}

RESUMO: Neste ensaio, abordamos questões necessárias para a compreensão do campo da Didática, partindo de estudos e pesquisas de pedagogos contemporâneos que nos permitem entender que a Didática estuda o processo de ensino por meio dos seus componentes- os conteúdos escolares, o ensino e a aprendizagem- para, com o embasamento na teoria da educação, formular diretrizes orientadoras da atividade profissional dos professores. Bem como que a lógica da didática é a lógica da produção da aprendizagem (nos alunos), a partir de processos de ensino previamente planejados. A prática da didática é, portanto, uma prática pedagógica, que inclui a didática e a transcende. A finalidade é discutir o campo da Didática, enquanto área da Pedagogia, cujo objetivo de estudo é o processo de ensino e aprendizagem. Para tanto, nesta discussão, discutimos, entre outros pontos: a Didática enquanto uma atividade de cunho pedagógico; notas sobre o campo da Didática; o papel da Didática; o ensino, enquanto objeto de estudo da Didática; o papel dos/as professores/as nos processos de ensino e aprendizagem a partir do campo da Didática.

PALAVRAS-CHAVE: Didática. Ensino e aprendizagem. Pedagogos contemporâneos.

RESUMEN: En este ensayo, abordamos cuestiones necesarias para la comprensión del campo de la Didáctica, empezando por estudios e investigaciones de pedagogos contemporáneos que nos permiten comprehender que la Didáctica estudia el proceso de enseñanza por medio de sus componentes- los contenidos escolares, la enseñanza y el aprendizaje- para con el fundamento en la teoría de la educación, formular directrices orientadoras de la actividad profesional de los profesores. La lógica de la didáctica es la lógica de la producción del aprendizaje (en los alumnos), a partir de procesos de enseñanza previamente planificados. La práctica de la didáctica es, por lo tanto, una práctica pedagógica que incluye la didáctica y la trasciende. La finalidad es discutir el

\footnotetext{
${ }^{1}$ Universidade Regional do Cariri (URCA), Missão Velha - CE - Brasil. Graduanda em Letras. E-mail: jamacarulocutora@outlook.com.

${ }^{2}$ Universidade Regional do Cariri (URCA), Missão Velha - CE - Brasil. Graduanda em Letras. E-mail: clovessantos0@gmail.com.

${ }^{3}$ Universidade Regional do Cariri (URCA), Missão Velha - CE - Brasil. Graduanda em Letras. E-mail: edivaniagomes1@outlook.com.

${ }^{4}$ Universidade Regional do Cariri (URCA), Missão Velha - CE - Brasil. Docente da Universidade Regional do Cariri. Doutorando em Educação pela Universidade Federal da Paraíba (UFPB). E-mail: osmarhelio@hotmail.com.
} 
campo de la Didáctica, en cuanto área de la Pedagogía, cuyo objetivo de estudio es el proceso de enseñanza y aprendizaje. Para ello, discutimos, entre otros puntos: la Didáctica como una actividad de cuño pedagógico; notas sobre el campo de la didáctica; el papel de la didáctica; la enseñanza, como objeto de estudio de la Didáctica; el papel de los / las profesores / as en los procesos de enseñanza y aprendizaje a partir del campo didáctico.

PALABRAS CLAVE: Didáctica. Enseñanza y aprendizaje. Pedagogos contemporáneos.

ABSTRACT: In this essay, we approach fundamental questions for the understanding of the field of Didactics, starting from studies and researches of contemporary pedagogues that allow us to understand that Didactics studies the teaching process through its components - school contents, teaching and learning-with the basis of the theory of education, to formulate directives guiding the professional activity of teachers. As well as that the logic of didactics is the logic of the production of learning (in the students), from previously planned teaching processes. The practice of didactics is, therefore, a pedagogical practice, that includes didactics and transcends it. The purpose here is to discuss the field of Didactics as an area of Pedagogy, whose objective is the teaching and learning process. To this end, we discuss, among other points: Didactics as an activity of a pedagogical nature; notes on the field of Didactics; the role of Didactics; teaching as an object of Didactic study; the role of teachers in the processes of teaching and learning from the field of Didactics.

KEYWORDS: Didactics. Teaching and learning. Contemporary pedagogues.

\section{Introdução}

Entendemos que a educação é um processo social que ocorre em diferentes espaços, cujo objetivo é a "[...] humanização dos homens, isto é, fazer dos seres humanos participantes dos frutos e da construção da civilização, dos progressos da civilização, resultado do trabalho dos homens" (PIMENTA, 2009, p. 84). Entendemos também que educação é "(...) o processo que visa à inserção das novas gerações na sociedade; trata-se de um fenômeno social, que acontece em diferentes espaços, sejam eles institucionalizados ou não" (MARQUES; PIMENTA, 2015, p. 138). Partindo desse entendimento e compreendendo que a atividade docente é uma das atividades da educação, enquanto processo social, queremos aqui discutir e problematizar o campo da Didática, posto que “[...] seu objetivo de estudo é o processo de ensino-aprendizagem sistemático e internacionalmente desenvolvido pela atividade educativa do professor" (PIMENTA, 2009, p. 107).

Este ensaio, portanto, problematiza o campo da Didática a partir de pedagogos contemporâneos/as, entre eles: Luckesi (2002); Silva (2002); Pimenta (2009); Libâneo 
(2010, 2013); Franco (2013, 2015, 2016); Pimenta (2014); Rios (2014); Pimenta e Marques (2015); Candau (2016), os quais nos permitem compreender que a Didática, assim como a Pedagogia, tem o compromisso com a transformação social por meio de um ensino eficiente que ocorre a partir de práticas pedagógicas que buscam “[...] construir uma educação escolar capaz de dar resposta aos desafios da contemporaneidade". Entretanto, é “[...] importante reinventar o campo da Didática [...]” (CANDAU, 2016, p. $334)$.

Logo, queremos destacar o lugar de destaque que a Didática ${ }^{5}$, enquanto teoria do ensino, deve ocupar na formação dos/as professores/as, pois a Didática, assim como a Pedagogia preocupam-se com a finalidade do que se ensina. Bem como "[...] constituemse em instrumental importante para ampliação da unidade entre a teoria e a prática do trabalho dos professores [...]" (PIMENTA, 2009, p. 107).

\title{
Materializando a discussão
}

Enfatizamos, a princípio, que a Didática é uma atividade de cunho pedagógico. Segundo Libâneo (2013, p. 53), "[...] a Didática assegura o fazer pedagógico na escola, na sua dimensão político-social e técnica; é, por isso, uma disciplina eminentemente pedagógica. Logo, como salienta ainda o autor:

\begin{abstract}
A Didática é, pois, uma das disciplinas da Pedagogia que estuda o processo de ensino por meio dos seus componentes - os conteúdos escolares, o ensino e a aprendizagem- para, com o embasamento na teoria da educação, formular diretrizes orientadoras da atividade profissional dos professores. É, ao mesmo tempo, uma matéria de estudo fundamental na formação profissional dos professores e um meio de trabalho do qual os professores se servem para dirigir a atividade de ensino, cujo resultado é a aprendizagem dos conteúdos escolares pelos alunos (LIBÂNEO, 2013, p.53).
\end{abstract}

Nesta perspectiva, "[...] o professor precisa saber organizar uma aula; planejar uma unidade de ensino; precisa dispor de exemplos e argumentos a respeito daquilo que está ensinando; precisa dar referências, oferecer perspectivas através de sua disciplina, do campo de saber" (FRANCO, 2013, p. 152). Logo, compreendemos que os professores, na sua grande maioria, necessitam entender a Didática enquanto atividade de cunho pedagógico que os possibilitará construir uma prática pedagógica em uma perspectiva de

${ }^{5}$ Ver: Araújo; Rodrigues; Aragão (2017). 
práxis ${ }^{6}$, isto é, ação - reflexão - ação, pois o professor precisa tomar a sua própria prática como objeto de reflexão. Logo, faz-se necessário sublinhar que "quem trabalha com formação de professores pode facilmente observar o desespero de professores frente ao próprio despreparo profissional e as dificuldades que têm para organizar a sua prática docente" (FRANCO, 2013, p. 217). Por isso queremos aqui sublinhar que a Didática, enquanto a teoria da instrução do ensino,

[...] investiga as condições e formas que vigoram no ensino e, ao mesmo tempo, os fatores reais (sociais, políticos, culturais, psicossociais) condicionantes das relações entre a docência e a aprendizagem. Ou seja, destacando a instrução e o ensino como elementos primordiais do processo pedagógico escolar, traduz objetivos sociais e políticos em objetivos de ensino, seleciona e organiza os conteúdos e métodos e, ao estabelecer as conexões entre ensino e aprendizagem, indica princípios e diretrizes que irão regular a ação didática (LIBÂNEO, 2013, p. 53).

Assim, de acordo com os estudos de Libâneo (2010, 2013), Franco (2016), Pimenta (2009), a Didática apresenta-se como um dos campos da Pedagogia. Logo, enquanto a Pedagogia se preocupa com o fenômeno educativo em sua totalidade, a Didática estuda o ensino, considerando todos os seus condicionantes. Ou seja, "A pedagogia caminha por entre culturas, subjetividades, sujeitos e práticas. Caminha pela escola, mas a antecede, acompanha-a e caminha além. A pedagogia interpõe intencionalidades, projetos alargados [...] (FRANCO, 2016, p. 542). Libâneo (2010, p. 30), na mesma linha de Franco, acrescenta que a "Pedagogia é, então, o campo do conhecimento que se ocupa do estudo sistemático da educação, isto é, do ato educativo, da prática educativa concreta que se realiza na sociedade como um dos ingredientes básicos da configuração da atividade humana".

Franco (2016, p. 542) nos leva a compreender que "A lógica da didática é a lógica da produção da aprendizagem (nos alunos), a partir de processos de ensino previamente planejados. A prática da didática é, portanto, uma prática pedagógica que inclui a didática e a transcende". Luckesi (2002, p. 26) entra no debate explicando que "[...] o papel da didática" destina-se a atingir um fim, "a formação do educador", seguido de Franco e Pimenta $(2014$, p. 08) que dão ênfase também que “[...] o papel da Didática se estrutura nas possibilidades de mediação entre o ensino, prioritariamente, na responsabilidade de

${ }^{6}$ Neste texto, “[...] práxis é entendida como a relação dialética entre homem e natureza, na qual o homem, ao transformar a natureza com seu trabalho, transforma a si mesmo" (FRANCO, 2016, p. 543). 
professores, e a aprendizagem dos alunos e de todos aqueles que, nesse momento, são alunos, porque estão em situação de aprender".

De modo geral, compreendemos o ensino, objeto de estudo da Didática, como já assinalado, como "[...] um processo social, integrante de múltiplos processos sociais, nos quais estão implicadas dimensões políticas, ideológicas, éticas, pedagógicas [...]" (LIBÂNEO, 2013, p. 58). Entretanto, é importante “[...] considerar o ensino como uma prática social específica, que se dá no interior de um processo de educação e que ocorre informalmente, de maneira espontânea, ou formalmente, de maneira sistemática, intencional e organizada". (RIOS, 2014. p. 14). Deste modo, é papel da Didática investigar os objetivos, conteúdos, meios e as condições para realização do ensino, pois a mesma deve voltar-se “[...] para o ensino que se desenvolve na instituição escolar, realizado a partir de sua organização curricular - definição de objetivos, organização de conteúdos [...] e métodos [...] avaliação do processo" (RIOS, 2014. p. 114). Também função da Didática levar o professor a refletir sobre o que ensina. Conforme afirma Libâneo (2013),

[...] o ensino não é só transmissão de informações, mas também o meio de organizar a atividade do aluno. $\mathrm{O}$ ensino somente é bem-sucedido quando os objetivos do professor coincidem com os objetivos de estudo do aluno e é praticado tendo em vista o desenvolvimento das suas forças intelectuais (LIBÂNEO, 2013, p.56).

Considerando as contribuições do autor, queremos sublinhar que há uma unidade entre ensino e aprendizagem, posto que "Ensinar e aprender, pois, são duas facetas do mesmo processo, e que se realizam em torno das matérias de ensino, sob a direção do professor" (LIBÂNEO, 2013, p. 56). Ou seja, como explica o mesmo autor, "A unidade ensino-aprendizagem se concretiza na interligação de dois momentos indissociáveis transmissão/assimilação ativa de conhecimentos e habilidades, dentro de condições específicas de cada situação didática" (LIBÂNEO, 2013, p. 82).

Nesta perspectiva, é papel dos professores construírem ações pedagógicas e saberes imbricados a seu compromisso social e político. Todavia, Franco (2015) explicita que:

[...] uma aula só se torna uma prática pedagógica quando ela se organiza em torno: de intencionalidades, de práticas que dão sentido às intencionalidades; de reflexão contínua para avaliar se a intencionalidade está atingindo todos; de acertos contínuos de rota e de 
meios para se atingir os fins propostos pelas intencionalidades (FRANCO, 2015, p. 605).

Nesse sentido, é preciso pensar em uma formação docente que instrumentalize os professores para um fazer docente que seja capaz de combinar “[...] objetivos, conteúdos, métodos e formas de organização do ensino, tendo em vista a assimilação ativa, por parte dos alunos, de conhecimentos, habilidades e hábitos e o desenvolvimento de suas capacidades cognoscitivas" (LIBÂNEO, 2013, p. 82). Ou seja, queremos enfatizar que a Didática possibilita aos professores desenvolver habilidades e competências a partir de um olhar crítico-reflexivo sobre a realidade educacional brasileira e, por consequência, a construírem práticas pedagógicas que oportunizem um ensino que se caracteriza "[...] pelo desenvolvimento e transformação progressiva das capacidades intelectuais dos alunos em direção ao domínio dos conhecimentos e habilidades, e sua aplicação" (LIBÂNEO, 2013, p. 84). Nessa mesma linha de pensamento, trazemos para o debate que

\footnotetext{
A escola deve prover aos alunos conhecimentos sistematizados que, contribuindo para o seu desenvolvimento intelectual, sejam úteis para a atividade permanente de estudo e para a vida prática. Sem o domínio dos conhecimentos não se desenvolvem as capacidades intelectuais, não é possível a assimilação de conhecimentos de forma sólida e duradoura (LIBÂNEO, 2013, p.86).
}

Assim, é necessário que os professores, envolvidos com seres humanos e comprometidos com a sua formação, busquem o que há de positivo em cada aluno e encontre um caminho para descobri-lo, para construir relações de proximidade e para acompanhá-lo em seu desenvolvimento cognitivo. De acordo com Libâneo (2013), “O ensino tem, portanto, como função principal assegurar o processo de transmissão e assimilação dos conteúdos do saber escolar e, através desse processo, o desenvolvimento das capacidades cognoscitivas dos alunos" (LIBÂNEO, 2013, p. 85).

Nesta perspectiva, aos professores/as, no cerne das escolas brasileiras, é reservado o papel especial de contribuir na formação de cidadãos críticos e reflexivos. Por isso é necessário que os docentes não foquem, sobretudo, nas fragilidades dos alunos, mas detenham-se no que existe de melhor nos mesmos e, por consequência, trabalhem procurando despertar o gosto pelo envolvimento e participação no processo de aprendizagem. Ou seja, “O professor não pode desistir do aluno. Há que insistir, ouvir, refazer, fazer de outro jeito, [...], descobrir e compreender as relações que ele estabelece 
com o saber, mudar o enfoque didático, as abordagens de interação e os caminhos do diálogo" (FRANCO, 2015, p. 606).

Neste ponto da discussão, queremos ressaltar que o processo de aprendizagem consiste na

[...] assimilação ativa de conhecimentos e de operações mentais, para compreendê-los e aplicá-los consciente e autonomamente. A aprendizagem é uma forma do conhecimento humano - relação cognitiva entre aluno e matéria de estudo - desenvolvendo-se sob as condições específicas do processo de ensino (LIBÂNEO, 2013, p. 85).

Sobre a assimilação ativa de conhecimentos, entendemos que esse processo envolve “[...] percepção, compreensão, reflexão e aplicação que se desenvolve com os meios intelectuais, motivacionais e atitudinais do próprio aluno, sob a direção e orientação do professor" (LIBÂNEO, 2013, p. 89). Ou seja, o processo de aprendizagem exige um professor que não se limite a falar sobre "o que se deveria aprender", como mestre do conhecimento que transmite informações típicas de um tempo aclamado como a era do conhecimento, mas, ao contrário, os processos de ensino e aprendizagem ocorrem por meio das práticas pedagógicas enquanto "[...] vivas, existenciais, interativas e importantes, por natureza" (FRANCO, 2016, p. 542). Silva (2002, p. 197) completa enfatizando que "O fazer didático é antes de tudo dinâmico, ativo, processual, construtivo e exige a permanente problematização da informação/conhecimento".

Logo, entendemos que

As práticas pedagógicas são aquelas que se organizam para concretizar determinadas expectativas educacionais. São práticas carregadas de intencionalidade uma vez que o próprio sentido de práxis se configura por meio do estabelecimento de uma intencionalidade, que dirige e dá sentido à ação, solicitando uma intervenção planejada científica sobre o objeto, com vistas à transformação da realidade social (FRANCO, 2016, p. 542).

Queremos enfatizar aqui que "Quando se fala em prática pedagógica, refere-se a algo além da prática didática, envolvendo: as circunstâncias da formação, os espaçostempos escolares, as opções da organização do trabalho docente, as parcerias e expectativas do docente" (FRANCO, 2016, p. 542). Entretanto, uma prática docente verdadeiramente pedagógica exige do/a professor/a conhecimentos do campo da Pedagogia, posto que ela “[...] investiga os objetivos sociopolíticos e os meios 
organizativos e metodológicos de viabilizar os processos formativos em contextos socioculturais específicos" (LIBÂNEO, 2010, p. 14).

Em linhas conclusivas, considerando que "a essência da atividade (prática) do professor é o ensino - aprendizagem" (PIMENTA, 2009, p. 83), queremos reiterar que a Didática tem uma contribuição específica nesse projeto, pois seu objetivo de estudo é o processo de ensino-aprendizagem sistemático e internacionalmente desenvolvido pela atividade educativa do professor (PIMENTA, 2009, p. 107), ou seja, reiteramos aqui que a Didática leva o/a professor melhorar o que é próprio seu, a sua prática e a sua formação. Ao mesmo tempo, a Didática contribui para a suplantação de práticas docentes que não se configuram como

\section{Considerações finais}

Para apresentar nossas considerações finais, entretanto, sempre provisórias, é necessário ressaltarmos que "É completamente irreal pensar que a didática sozinha possa produzir mudanças na prática docente!!! A didática pode produzir teorias que dialogam com as práticas. No entanto, para a existência desse diálogo, são necessárias condições de trabalho ao docente" (FRANCO, 2013, p.159). Assim como a valorização das experiências docentes bem-sucedidas, a criação de estruturas pedagógicas transformadoras, formadoras, ou seja, uma formação docente que permita ao professor espaço/tempo para discutir um projeto pedagógico coletivo e transformar.

Por fim, por satisfeitos ficaremos se as ideias aqui ventiladas possibilitarem cada professor perceber que somente "[...] quando os alunos compreendem solidamente a matéria, são capazes de pensar de forma independente e criativa sobre ela e aplicar o que foi assimilado" (LIBÂNEO, 2013, p. 114) é que, de fato, a Didática cumpre seu papel por meio de uma prática pedagógica transformadora.

\section{REFERÊNCIAS}

ARAÚJO, Osmar Hélio Alves.; RODRIGUES, Janine Marta Coelho.; ARAGÃO, Wilson Honorato. O (des) lugar da pedagogia e da didática na formação dos professores. Revista on line de Política e Gestão Educacional, Araraquara, v. 21, n. 1, p. 215-226, 2017. Disponível em: <http://dx.doi.org/10.22633/rpge.v21.n.1.2017.9534>. Acesso em: 10 jun. 2017. 
CANDAU, Vera Maria Ferrão.; KOFFI, Adélia Maria Nehme Simão e. A Didática hoje: reinventando caminhos. Educação \& Realidade, Porto Alegre, v. 40, n. 2, p. 329348, abr./jun. 2015. Disponível em:

<http://www.scielo.br/scielo.php?script=sci_arttext\&pid=S2175-62362015000200329>. Acesso em: 02 maio 2016.

FRANCO, Maria Amélia Santoro. Didática: uma esperança para as dificuldades pedagógicas do Ensino superior? Práxis Educacional, v. 9, n. 15, 2013. Disponível em: <http://periodicos.uesb.br/index.php/praxis/article/view/1947>. Acesso em: 04 maio 2016.

FRANCO, Maria Amélia Santoro.; PIMENTA, Selma Garrido. Apresentação. In: FRANCO, Maria Amélia Santoro.; PIMENTA, Selma Garrido. (Orgs.). Didática: embates contemporâneos. $3^{a}$ ed. São Paulo: Edições Loyola, 2014. p. 07-41.

FRANCO, Maria Amélia do Rosário Santoro. Práticas pedagógicas de ensinar-aprender: por entre resistências e resignações. Educ. Pesqui., São Paulo, v. 41, n. 3, p. 601-614, jul./set. 2015. Disponível em: <http://www.scielo.br/pdf/ep/v41n3/1517-9702-ep-41-30601.pdf>. Acesso em: 03 maio 2016.

FRANCO, Maria Amélia do Rosário Santoro. Prática pedagógica e docência: um olhar a partir da epistemologia do conceito. Rev. bras. Estud. pedagog. (on-line), Brasília, v. 97, n. 247, p. 534-551, set./dez. 2016. Disponível

em:<http://www.scielo.br/pdf/rbeped/v97n247/2176-6681-rbeped-97-247-00534.pdf>. Acesso em: 08 fev. 2017.

LIBÂNEO, José Carlos. Pedagogia e pedagogos, para quê? São Paulo: Cortês, 2010.

LIBÂNEO, José Carlos. Didática. 2 ed. São Paulo: Cortez, 2013.

LUCKES, Cipriano Carlos. O Papel da Didática na Formação do Educador. In: CANDAU, Vera Maria (Org.). A didática em questão. 28 ed. Petrópolis, RJ: Vozes, 2008. p. 25-34.

MARQUES, Amanda Cristina Teagno Lopes.; PIMENTA, Selma Garrido. É possível formar professores sem os saberes da pedagogia? uma reflexão sobre docência e saberes. Revista Metalinguagens, n. 3, maio 2015, p. 135-156. Disponível em: $<$ http://metalinguagens.spo.ifsp.edu.br/wp-content/uploads/2015/05/Amanda-CristinaTeagno-Lopes-MARQUES-e-Selma-Garrido-PIMENTA.pdf>. Acesso em: 28 abr. 2017.

PIMENTA, Selma Garrido. O estágio na formação de professores: unidade teoria e prática? 8. ed. São Paulo: Cortez, 2009.

RIOS, Terezinha Azerêdo. Ampliar o diálogo de saberes para a docência. In: FRANCO, Maria Amélia Santoro.; PIMENTA, Selma Garrido. (Orgs.). Didática: embates contemporâneos. $3^{a}$ ed. São Paulo: Edições Loyola, 2014. p.101-130. 
SILVA, Ainda Maria Monteiro. Da didática em questão às questões da Didática. In: CANDAU, Vera Maria. Didática, currículo e saberes escolares. Rio de Janeiro: DP\&A, 2002. p. 188- 197.

\section{Como referenciar este artigo}

DANTAS, Rosana de Oliveira Rodrigues.; MORAES, Cloves Santos de.; SILVA, Edivania Gomes da.; ARAÚJO, Osmar Hélio Alves. A didática a partir de pedagogos contemporâneos. Temas em Educ. e Saúde, Araraquara, v.13, n.2, p. 187-196, jul./dez. 2017. Disponível em: <https://doi.org/10.26673/rtes.v13.n2.jul-dez.2017.10402>. EISSN: 2526-3471.

Submetido em: 16/09/2017

Aprovado em: 01/11/2017 